\title{
Rosella Flower Decreases the CML Serum and Liver Inflammation of Rats Given Baked-Food Diet
}

\author{
Silvy A. Falyani ${ }^{1,2}{ }^{2}$, Setyawati Karyono ${ }^{3}$, Edi Widjajanto ${ }^{4}$, Ardhiyanti P. Ratna ${ }^{1}$, Pia B. \\ Batmomolin ${ }^{1}$ \\ ${ }^{1}$ Master Program of Biomedic, Faculty of Medicine, University of Brawijaya, Malang, Indonesia \\ ${ }^{2}$ Department of Pathology Anatomy, Malang Islamic University, Malang, Indonesia \\ ${ }^{3}$ Department of Pharmacology, Faculty of Medicine, University of Brawijaya, Malang, Indonesia \\ ${ }^{4}$ Department of Clinical Pathology, Faculty of Medicine, University of Brawijaya, Malang, Indonesia
}

\begin{abstract}
Advanced Glycation Endproducts (AGEs) or so-called glycotoxin can be triggered by heated food in which the Maillard reaction occurs. One type of glycotoxins is CML. Accumulated N-Carboxymethyl-Lysine (CML) can cause inflammation of organs, e.g. liver. Rosella flowers contain anthocyanin compound that has anti-glycation and antioxidant effects. This study aimed to determine the effect of ethanol extract of Rosella on CML serum level, IL-6 level, and NF-kB activation in the liver of mice fed with baked food. This study used post-test design using 25 Wistar rats aged 3-4 months old that were divided into 5 groups, namely negative control group, positive control group, treatment groups given Rosella extract dose of $200 \mathrm{mg} . \mathrm{kgBW}^{-1}, 300 \mathrm{mg} . \mathrm{kgBW}^{-1}$, and $400 \mathrm{mg} . \mathrm{kgBW}^{-1}$. Baked feed was given for 12 weeks, and Rosella ethanol extract was administered in the $9^{\text {th }}$ to $12^{\text {th }}$ week. The examination on CML serum and IL- 6 of the liver was using ELISA method. Immunofluorescent staining was used to determine NF-KB activation in the liver using a confocal microscope. CML serum is proven to increase significantly $(p=0.000)$. The effective dose of Rosella flower extract to prevent CML Serum increase is $200 \mathrm{mg} \cdot \mathrm{kgBW}^{-1}$, whereas a dose of $400 \mathrm{mg} \cdot \mathrm{kgBW}^{-1}$ can decrease IL-6 level and NF-kB activation. Ethanol extract of Rosella flower decrease the levels of N-carboxymethyl-lysine serum, IL-6, and NF-kB activation in the liver of rats given baked-food diet.
\end{abstract}

Keywords: Advanced Glycation Endproducts (AGEs), Interleukin-6, N-Carboxymethyl-lysine, Rosella.

\section{INTRODUCTION}

Modernization results in major changes in human behavior. Being busy due to working activities is one of the reasons for people to seek more practical food. Preparing dishes by steaming or frying method have been shifted into cooking using oven and other new technologies. In fact, heating at high temperatures can increase the level of Advanced Glycation Endproducts (AGEs) or called glycotoxin. Glycotoxin is a compound formed from non-enzymatic glycation reactions between proteins and sugar residues. The best known of Glycotoxin type is $\mathrm{N}$ carboxymethyl-lysine (CML), pentosidine, pyrraline, and methylglyoxal. CML is often used as a marker for the formation of glycotoxin, as CML is a glycotoxin type which is most common and best known for in vivo characterization [1].

Glycotoxin accumulate in many tissues of the body, and when accumulated, it increases the inflammatory reaction, weakens the immune

\footnotetext{
* Correspondence author:

Silvy Amalia Falyani

Email : silvyamaliafalyani@gmail.com

Address : Biomedical Program, Faculty of Medicine, University of Brawijaya, Veteran St. Malang 65145
}

system, increases the infection possibilities, lowers the antioxidant defense mechanism, interferes DNA repair mechanisms, and increases the accumulation of various kinds of toxins [2,3].

Liver functions in metabolism are not excluded from glycotoxin accumulation. Liver cell damage can occur due to inflammatory reactions and oxidative stress [4]. NF-kB which is a transcription factor in mammals controls a number of important genes in immunity and inflammatory processes. NF-kB activation will stimulate proinflammatory cytokines such as Interleukin-6 (IL6), and increase NF-kB activation that can be a marker of organ inflammation.

Anthocyanin is a type of polyphenols known as antioxidants among the group of flavonoids. Anthocyanin is known to inhibit glycation process and glycotoxin binding to its receptor, as well as to prevent lipid peroxidation and polyol pathway inhibition [5,6].

Hibiscus sabdariffa L. or commonly known as Rosella empirically has been consumed by humans in some parts of the world. In vitro and in vivo researches prove beneficial phytochemical content in Rosella flower extract. Rosella flower extract is known to offer antibacterial effect, an- 
tioxidant, hepato and nefro-protective, antiinflammatory, and anti-cholesterol $[7,8]$.

By considering the work of anthocyanin as AGE inhibitor, antioxidant, and anti-inflammatory, it raised presumption that Rosella flower ethanol extract can repair liver damage caused by glycotoxin. Within this assumption, the researchers wanted to determine the effect of Rosella flower (Hibiscus sabdariffa L.) ethanol extract in inhibiting pro-inflammatory signaling pathways of liver tissue mediated by $\mathrm{N}$ carboxymethyl-lysine in Wistar rats given bakedfood diet.

\section{MATERIALS AND METHODS Subject}

This study used post-test design that compares the control and the treatment groups. Animals used were 25 male Wistar rats aged 3-4 months old with 100-150 gram initial body weight. Rats that were ill or died during the research were excluded from the population.

Rats were adapted to research environment condition for 1 week, and fed with standard feed and drinking water in ad libitum method. Rats were placed in cages measuring $\pm 900 \mathrm{~cm}^{3}$ for $4-5$ rats. After passing the adaptation stage, the rats were weighed to determine the initial weight, then the rats were randomly divided into five groups that consisted 5 rats each. Furthermore, each rat was placed in a different enclosure. Negative control group (KN) was fed with standard diet, while positive control group (KP) and treatment groups given Rosella extract dose of $200 \mathrm{mg} \cdot \mathrm{kgBW}^{-1}\left(\mathrm{KR}_{1}\right)$, 300mg.kgBW ${ }^{-1}\left(\mathrm{KR}_{2}\right)$, and $400 \mathrm{mg} . \mathrm{kgBW}^{-1}\left(\mathrm{KR}_{3}\right)$ were fed with baked food for 8 weeks. After 8 weeks, CML serum level measurement was conducted using ELISA method.

Broiler feed 1 (BR1) was used because it contains the highest protein than other feeds. This feed contains $21-23 \%$ protein, $5 \%$ fat, 40 $45 \%$ starch and $5 \%$ crude fiber. Oven was preheated at $150{ }^{\circ} \mathrm{C}$ for 15 minutes.

\section{Treatments and Data Collection}

At $9^{\text {th }}$ week, provisions of Rosella flower ethanol extract were given to the treatment group $K R_{1}, K R_{2}$, and $K R_{3}$ as much as 200 mg.kgBW ${ }^{-1}$, 300 mg.kgBW $^{-1}$, and 400 mg.kgBW $^{-1}$ respectively for 4 weeks. Baked food feeding was expected to be given until the $12^{\text {th }}$ week.

At $13^{\text {th }}$ week, the animals were dissected. Blood was drawn intracardially for $\mathrm{CML}$ examination using ELISA kit (Bioassays, Number catalogs E1374Ra). Livers harvesting were performed for NF-kB activation examination using immunofluorescent method using primary NF-kB P65 antibody (ThermoFisher, Number catalog MA5-15160), hepatic IL-6 examination was using ELISA kit (Bioassays, catalog Number E0135Ra), and hepatic organ staining was using Haematoxylin-eosin.

\section{Data Analysis}

Once the data were obtained, the data were statistically analyzed using SPSS 24.0. Data normality test was done using Shapiro-Wilk test. Data homogeneity was analyzed using Levene's Test. Data comparison was using independent ttest, ANOVA, and Post Hoc. Results can be said significant when $P<0.05$.

\section{RESULTS}

\section{Serum Levels}

Assessment on the effect of Rosella flower ethanol extract on CML serum levels in rats given baked food was done using ANOVA test. The rats' CML serum levels were obtained using ELISA kit (Bioassays, catalog Number E1374Ra). Figure 1 is a histogram of CML serum levels. The histogram shows that increased levels of CML serum in mice are between negative and positive control group. Levels of CML serum in treatment groups are lower than those of the positive control group. It proves that Rosella flower ethanol extract influences the final levels of Rats' CML level.

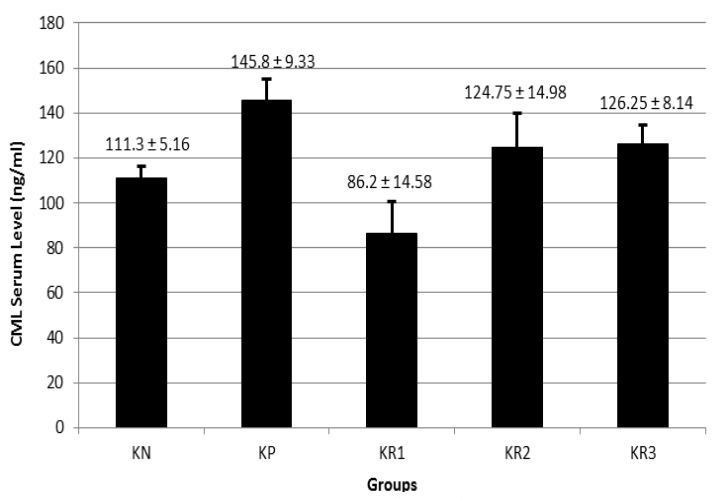

Figure 1. CML Serum Levels with ANOVA Test

Description: $\mathrm{KN}$ is negative control group (standard feed, without extract), KP is positive control group (fed with baked food, without extract), $\mathrm{KR}_{1}$ is treatment group 1 (fed with baked food + Rosella flower ethanol extract 200 $\mathrm{mg} \cdot \mathrm{kgBW}^{-1}$ ), $\mathrm{KR}_{2}$ is treatment group 2 (fed with baked food + Rosella flower ethanol extract $300 \mathrm{mg} \cdot \mathrm{kgBW}_{-1}$ ), and $\mathrm{KR}_{3}$ is treatment group 3, (fed with baked food + Rosella flower ethanol extract 400 mg.kgBW ${ }_{-1}$ ) 
There is a significant difference $(p=0.001)$ between the negative control group and positive control group. It indicates that baked food has an influence or affects the results of rats' CML serum. The positive control group has a significant difference compared with treatment group 2 ( $p=$ 0.05). It demonstrates that Rosella flower ethanol extract dose of $300 \mathrm{mg} \cdot \mathrm{kgBW}^{-1}$ can prevent increasing CML serum levels of rats fed with baked food.

\section{Hepatic NF-kB Activation}

Assessment on Rosella flower ethanol extract effect to hepatic NF-kB activation of rats fed with baked food were evaluated based on the amount of transcription factor expression of activated NFKB so that translocate from the cytoplasm to the nucleus of liver tissue was examined using immunofluorescent method with p65 antibody (ThermoFisher, catalog Number MA5-15 160).

Figure 2 is a histogram of hepatic NF-kB activation with ANOVA test. The histogram shows that when the control groups are compared, the positive control group has higher results compared to the negative control group. This might indicate that there were more hepatic NF-kB activations in the positive control group. The treatment group 3 has the lowest result compared with other treatment groups. This showed that the provisions of Rosella flower ethanol extract dose of $400 \mathrm{mg} \cdot \mathrm{kgBW}^{-1}$ were effective in suppressing NF-kB activation in liver of rats fed with baked food. A comparative figure of each group using immunoflourescent method and haemato-xylen eosin showed in Figure 3.

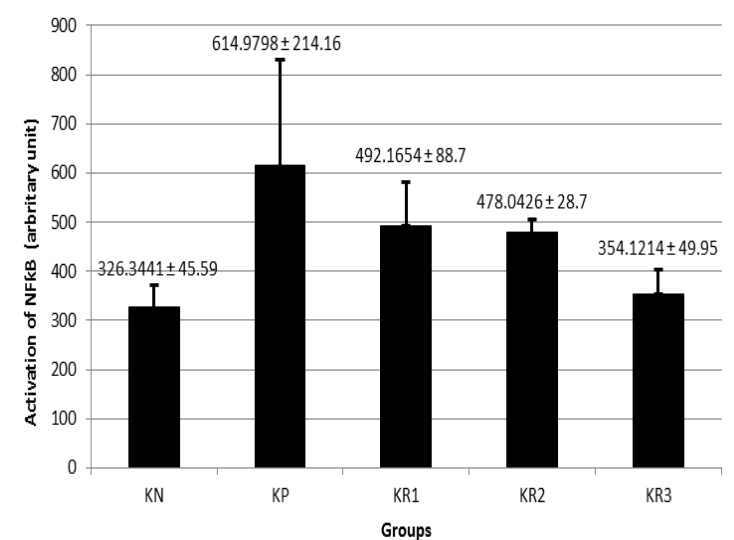

Figure 2. Histogram of Hepatic NF-kB Activation using ANOVA test

Description: KN is negative control group (standard feed, without extract), KP is positive control group (fed with baked food, without extract), $K R_{1}$ is treatment group 1 (fed with baked food + Rosella flower ethanol extract 200 mg.kgBW ${ }^{-1}$ ), $K R_{2}$ is treatment group 2 (fed with baked

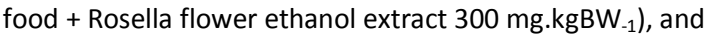

$\mathrm{KR}_{3}$ is treatment group 3, (fed with baked food + Rosella flower ethanol extract $400 \mathrm{mg} \cdot \mathrm{kgBW}_{-1}$ )
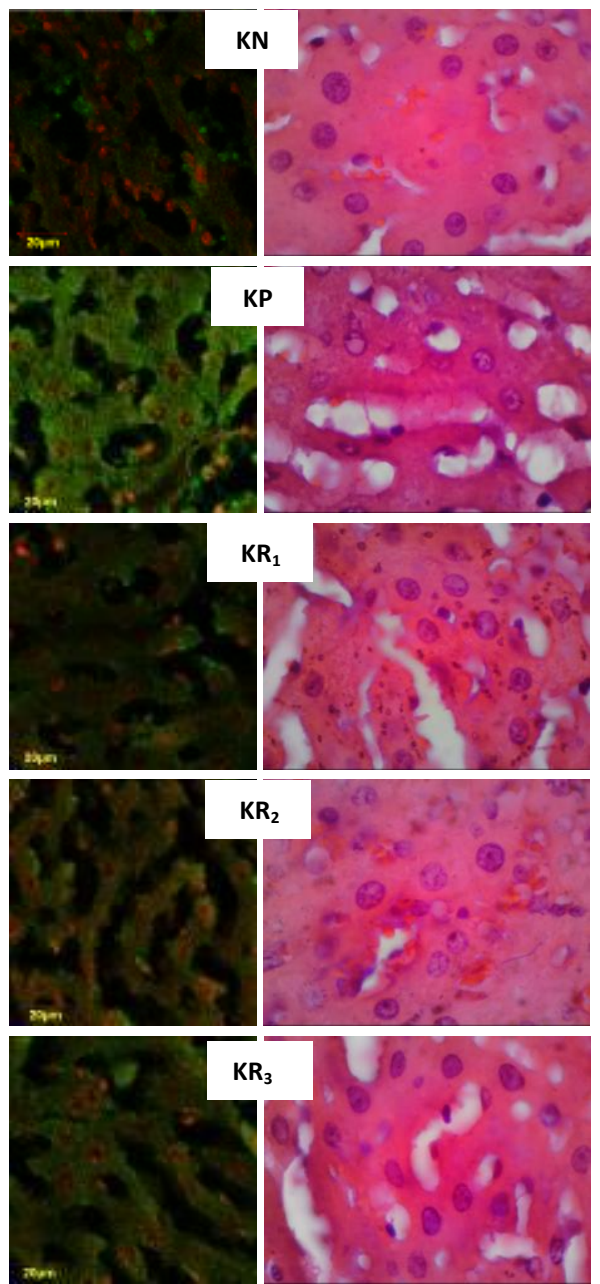

Figure 3. The Comparative Picture of Each Group Using Immunofluorescent Method and Haematoxylen Eosin

Description: KN is negative control group (standard feed, without extract), KP is positive control group (fed with baked food, without extract), $K R_{1}$ is treatment group 1 (fed with baked food + Rosella flower ethanol extract 200 $\mathrm{mg} \cdot \mathrm{kgBW}^{-1}$ ), $\mathrm{KR}_{2}$ is treatment group 2 (fed with baked food + Rosella flower ethanol extract 300 mg.kgBW-1), and $\mathrm{KR}_{3}$ is treatment group 3, (fed with baked food + Rosella flower ethanol extract $400 \mathrm{mg} \cdot \mathrm{kgBW}_{-1}$ ).

The observation was using a confocal microscope Olympus FV 1000 and calculated using Olympus Fluoview Version. 1.7a software.

Figure 3 is a comparative picture of each group using immunofluorescent and haematoxylen eosin. The calculated amount of NF-kB activation is the amount contained in the nucleus and appears red in the green color. 


\section{IL-6 levels}

IL-6 levels in liver tissue are pro-inflammatory cytokine levels that may become an inflammation indicator, the levels in rats' liver tissue (units of ng. $\mathrm{mL}^{-1}$ ) are measured using ELISA method (ELISA kit such as Bioassays, catalog Number E0135Ra).

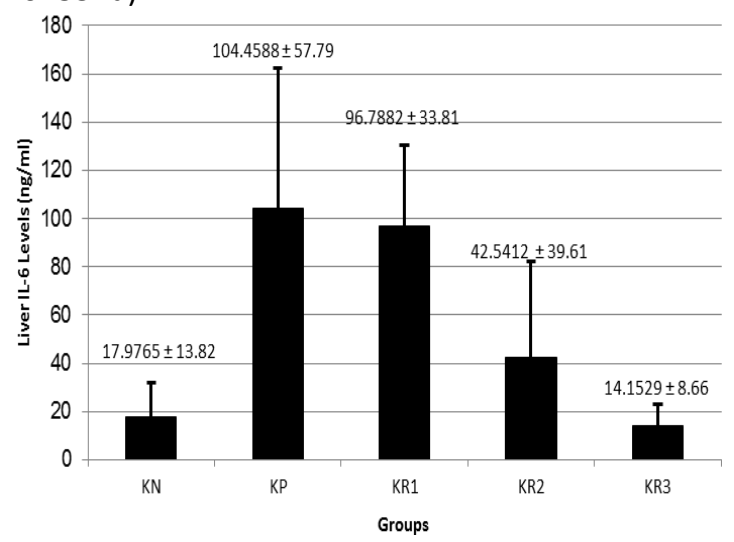

Figure 4. Histogram of IL-6 Levels using ANOVA test

Description: KN is negative control group (standard feed, without extract), KP is positive control group (fed with baked food, without extract), $\mathrm{KR}_{1}$ is treatment group 1 (fed with baked food + Rosella flower ethanol extract 200 $\mathrm{mg} . \mathrm{kgBW}^{-1}$ ), $\mathrm{KR}_{2}$ is treatment group 2 (fed with baked food + Rosella flower ethanol extract 300 mg.kgBW -1 ), and $\mathrm{KR}_{3}$ is treatment group 3, (fed with baked food + Rosella flower ethanol extract $400 \mathrm{mg} . \mathrm{kgBW}_{-1}$ )

Figure 4 is a histogram of IL- 6 levels of rats' liver. The histogram shows that there is an increase in IL- 6 levels in rats between negative and positive control group. IL-6 levels of treatment groups show lower results than the positive control group. It explains that Rosella flower ethanol extract influences and affectes the levels of $\mathrm{CML}$ serum on rats. The histogram may also prove that Rosella flower ethanol extract dose of 400 mg. kgBW ${ }^{-1}$ in treatment group 1 is proven to be more effective to reduce IL- 6 levels of rats fed with baked food.

\section{DISCUSSION}

This study used Wistar rats as they are easily maintained and relatively healthy, so that it meets the criteria as experimental animals in a study. Anatomical and physiological study of rats supports a nutrition experiment by using ad libitum method. There are two characters that distinguish rats from other laboratory animals, namely rats cannot vomit because of the unusual anatomical structure in the esophagus, which empties into the stomach, and has no gallbladder. This study used rats aged 2-3 months, which is analogically the age of reproductively mature or adolescence in rats [9].

Oral baked food feeding has advantages and disadvantages. Glycotoxin absorption of oral consumption is as much as $10 \%$ on the peak absorption at 6-12 hours after consumption. Glycotoxin duration in the body is 72 hours, and after 72 hours, $1 / 3$ of the total absorbed will be eliminated by kidneys [10]. Glycotoxin bioavailability depends on the peptide size, the food type, the intestinal environment, and the presence duration in intestine. Glycotoxin can be easily distributed to the extracellular and intracellular compartments because it has an amphoteric character and soluble in water. Studies in animals have shown that after 72 hours, $60 \%$ of the total absorbed glycotoxin will be bound in the liver and kidneys, but the radioactivity was detected in the lungs, the heart, and the spleen. This gives an indication that glycotoxin is distributed throughout all body tissues. Glycotoxin elimination occurs through the kidneys, and lasts for 72 hours after ingestion [10].

Rats which were given the baked food have shown more increasing levels of $\mathrm{N}$ Carboxymethyl-Lysine (CML). CML is one of glycotoxins derived from food [1]. There are three paths of glycotoxin formation, namely Maillard reaction, glucose oxidation and lipid peroxidation, as well as the polyol pathway. The variation of pathway formation causes various glycotoxin chemical structures. The best-known glycotoxin type is carboxymethyl-lysine $(\mathrm{CML})$, pentosidine, pyrraline, and methylglyoxal [1]. Among many types of glycotoxin, CML is the most possible type that can be characterized. CML is first identified in food, and it becomes the most frequent marker often used for research as a marker of increasing level of glycotoxin [11]. In this study, the p-value obtained was 0.001 ( $p$ $<0.05$ ). It clearly explains that there is a significant difference between the initial and the result of CML serum levels of the negative control group and the positive control group. This is consistent with result of previous research that explains glycotoxin content can increase by $10-100$ times by heating process [10].

When food is heated, there is a transformation of electromagnetic wave energy into heat energy. Previously, heating by using microwave has shown to increase the Maillard reaction and other chemical reactions significantly [11]. Maillard reaction is greatly influenced by the heating time, temperature, concentration, humidity, and acidity. In some previous studies, the Maillard 
reaction rate would double if the temperature rises $10^{\circ} \mathrm{C}$. If the Maillard reaction rate is characterized by a change into brownish color on the food, then heating either for 4 weeks at a temperature of $20^{\circ} \mathrm{C}, 3$ hours at a temperature of $100^{\circ} \mathrm{C}$, or 15 minutes at a temperature of $150^{\circ} \mathrm{C}$ will give the same result [12]. This is consistent with the results of this study, that there is an increase in CML serum as much as three times higher than that of the negative control group.

In this study, rats that are induced with baked food, and then treated with provisions of Rosella flower (Hibiscus sabdariffa L) ethanol extract

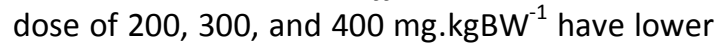
levels of CML serum, compared to the positive control group. There is a significant difference ( $P$ $<0.05$ ) in groups of rats given dose of 200 and 300 mg.kgBW ${ }^{-1}$ Rosella flower ethanol extract.

Rosella flower ethanol extract contains anthocyanin pigments. Anthocyanin is a type of antioxidants in the group of flavonoid. Anthocyanin is found in fruits and vegetables, especially those having red, blue, or purple colors. Anthocyanin has pigment colors that can dissolve in water and gives red, purple, and blue colors in many fruits, vegetables, flowers and seeds [13]. Anthocyanin is one type of polyphenols that can prevent glycotoxin formation. A study explains that phenolic antioxidants, in addition as a free radical scavenger, are serving as an AGE inhibitor [14]. Anthocyanin can inhibit the formation glycotoxin through inhibition of auto-oxidation monosaccaride [15]. Anthocyanin also inhibits the glycation process and binds glycotoxin with its receptor as well as prevents lipid peroxidation, and inhibits polyol pathway [5]. This is consistent with this research result where the CML serum levels of rats in the treatment group were lower than that in the positive control group.

The effective dose of Rosella flower ethanol extract to prevent an increase in CML is expected at a dose of $300 \mathrm{mg} . \mathrm{kgBW}^{-1}$. This result almost similar to previous research that mentioned the effective dose in lowering blood glucose levels of mice induced by Streptozocin is $288 \mathrm{mg}$ Rosella flower extract [16].

Nowadays, herb medication is still being subject of debate because the doses given are not always on target. Although antioxidant is highly contained in herb, it does not necessarily give a good effect on human body. Polyphenols may become pro-oxidants when given in high doses $[17,18]$. Pro-oxidants can trigger cell damage through oxidative stress mechanisms. Oxidative stress conditions can trigger glycation, so that pro-oxidant provision can increase the possibility of glycation. This is consistent with the results of this study in which levels of serum CML, as a marker of glycation end products, are likely to increase in the provision of higher Rosella flower extract.

The study also shows hepatic NF-kB activation as a transcription factor by using the control and treatment groups. The treatment groups were divided into doses of 200, 300, and 400 mg.kgBW ${ }^{-1}$. Assessments of Rosella flower ethanol extract effecting hepatic NF-KB activation of rats fed with baked food are evaluated based on the amount of transcription factor expression of activated NF-kB so that translocate from the cytoplasm to the nucleus on the liver tissue was examined using immunofluorescent method with p65 antibody.

The ANOVA test results shows the $p$-value was 0.003 ( $p>0.05)$, it is indicated that there is a significant effect of ethanol extract of Rosella flower to the activation of NF-kB liver of rat fed with baked food. There are significant differences in the positive control group with the group given dose of $400 \mathrm{mg} . \mathrm{kgBW}^{-1}$. This is consistent with the hypothesis that ethanol extract of Rosella flower may prevent an increase in NF-kB activation in liver.

NF-kB that is a transcription factor in mammal controls a number of genes that are important in immune and inflammatory processes. Some examples of these genes are Ig-k light chains, T-cell receptor $\alpha$ and $\beta$ chains, MHC class I proteins and cytokines such as GM-CSF, IL-6, IL-2 and TNF- $\alpha$. Viruses like HIV use NF-kB to activate its gene transcription [19]. Inflammation is known to contribute to the pathophysiology of many chronic diseases. When the inflammatory process continues over time, it damages the surrounding tissue, disrupts the network functions, and may cause widespread the damage of organs. This process will then lead to various diseases [4]. Rosella flower ethanol extract which has a compound of anthocyanin as antioxidant is expected to decrease the inflammation due to activation of pro-inflammatory cytokines.

This study also assesses IL-6 level in the liver, where there is a significant correlation between the positive control group with the treatment group given Rosella flower ethanol extract dose of $400 \mathrm{mg} . \mathrm{kgBW}^{-1}$ ( $p<0.05$ ). This is certainly in line with the results of NF-kB activation, where the effective dose of extract is $400 \mathrm{mg}^{\mathrm{kgBW}}{ }^{-1}$. 


\section{CONCLUSION}

Baked Animal Feed can increase Ncarboxymethyl-lysine (CML) serum levels of rats. Rosella flower ethanol extract dose of 200 mg.kgBW ${ }^{-1}$ decreases CML serum levels of rats fed with baked food. Rosella flower ethanol extract dose of $400 \mathrm{mg} \cdot \mathrm{kgBW}^{-1}$ prevents the increase of IL- 6 level and the NF-KB activation in the liver.

\section{REFERENCES}

[1] Luevano-Contreras, C., K. ChapmanNovakofski. 2010. Dietary Advanced Glycation End Products and aging. Nutrients. 2(12). 1247-1265.

[2] Bengmark, S. 2007. Advanced Glycation and Lipoxidation End Products - amplifiers of inflammation : the role of food. J. Parenter. Enter. Nutr. 31(5). 430-440.

[3] Ramasamy, R., S.J. Vannucci, S.S. Yan, K. Herold, S.F. Yan, A.M. Schmidt. 2005. Advanced glycation end products and RAGE: a common thread in aging, diabetes, Neurodegeneration, and Inflammation. Glycobiol. 15(7). 16R-28R.

[4] Kumar, V., A.K. Abbas, N. Fausto, S.L. Robbins, R.S. Cotran. 2005. Robbins and Cotran Phatologic Basic of Disease, $15^{\text {th }} \mathrm{Ed}$. Philadepphia: Elsevier Saunders. 23(5). 482483.

[5] Vauzour, D., A.R. Mateos, G. Corona, M.J. Oruna-Concha, J.P.E. Spencer. 2010. Polyphenols and human health : prevention of disease and mechanisms of action. Nutrients. 2(11). 1106-1131.

[6] Yawadio, R., S. Tanimori, N. Morita. 2007. Identification of phenolic compounds isolated from pigmented rices and their Aldose Reductase Inhibitory activities. Food Chem. 101(4). 1616-1625.

[7] Hirunpanich, V., A. Utaipat, N.P. Morales, N. Bunyapraphatsara, H. Sato, A. Herunsale, C. Suthisisang. 2006. Hypocholesterolemic and antioxidant effects of aqueous extracts from the dried calyx of Hibiscus sabdariffa L. in hypercholesterolemic rats. J. Ethnopharmacol. 103(2). 252-260.

[8] Fathoni, Z.U., R. Indra, Supranowo. 2014. Ekstrak rosela menurunkan perlemakan dan ekspresi ADMA hepar akibat diet aterogenik pada tikus. Jurnal Kedokteran Brawijaya. 28(1). 6-10.

[9] Sengupta, P. 2013. The laboratory rat: relating its age with human's. Int. J. Prev. Med. 4(6). 624-630.
[10] Uribarri, J., S. Woodruff, S. Goodman, W. Cai, X. Chen, R. Pyzik, A. Yong, G.E. Striker, H. Vlassara. 2010. Advanced Glycation End Products in foods and a practical guide to their reduction in the diet. J. Am. Dietetic Assoc. 110(6). 911-916.

[11] Lin, L., L. Han, Q. Fu, Z. Liang, J. Su, B. Li. 2012. Formation and inhibition of $\mathrm{N} \varepsilon$ (Carboxymethyl)lysine in Saccharide-Lysine model systems during microwave heating. Molecules. 17. 12758-12770.

[12] Poulsen, M.W., R.V. Hedegaard, J.M. Andersen, B. de Courten, S. Bügel, J. Nielsen, L.H. Skibsted, L.O. Dragsted. 2013. Advanced Glycation End Products in food and their effects on health. Food Chem. Toxicol. 60. 10-37.

[13] Shipp, J., E.M. Abdel-Aal. 2010. Food applications and physiological effects of anthocyanins as functional food ingredients. The Open Food Sci. J. 4. 7-22.

[14] Matsuda, H., T. Morikawa, I. Toguchida, M. Yoshikawa. 2002. Structural requirements of flavonoids and related compounds for Aldose Reductase inhibitory activity. Chem. Pharm. Bull. 50(6). 788-795.

[15] Rahbar, S., L. Figarola. 2003. Novel inhibitors of advanced glycation end products. Arch. Biochem. Biophys. 419(1). 63-79.

[16] Mardiah, R.Z. Fransiska, P. Endang, D. Rizal. 2015. Anti-inflammatory of purple roselle extract in diabetic rats induced by Streptozotocin. Procedia Food Sci. 3. 182189.

[17] Lambert, J.D., R.J. Elias 2010. The antioxidant and pro-oxidant activities of green tea polyphenols: a role in cancer prevention. Arch. Biochem. Biophys. 501(1). 65-72.

[18] Yordi, E.G., E.M. Perez, M.J. Matos, E.U. Villares. 2012. Antioxidant and pro-oxidant effects of polyphenolic compounds and structure activity relationship evidence. Nutr. Well-being Health. 10-27.

[19] Muller, C.W., F.A. Rey, M. Sodeoka, G.L. Verdine, S.C. Harrison 1995. Structure of the NF-kappa B p50 homodimer bound to DNA. Nature. 26. 373(6512). 311-317. 